\title{
LA CONFERENCIA DE PRESIDENTES: ORIGEN, EVOLUCIÓN Y PERSPECTIVAS DE REFORMA
}

JAVIER TAJADURA TEJADA 
SUMARIO

1. INTRODUCCIÓN. 2. LA CONFERENCIA DE PRESIDENTES Y EL DESARROLLO DEL PRINCIPIO CONSTITUCIONAL DE COOPERACIÓN. 3. NATURALEZA Y CARACTERES DE LA INSTITUCIÓN. 4. LA DOBLE CONFIGURACIÓN (HORIZONTAL Y VERTICAL) DE LA CONFERENCIA DE PRESIDENTES. 5. LA COMPOSICIÓN DE LA CONFERENCIA Y LA OBLIGACIÓN DE ASISTIR. 6. EL FUNCIONAMIENTO DE LA CONFERENCIA. 7. CONCLUSIONES: UNA PROPUESTA DE CONSTITUCIONALIZACIÓN DE LA CONFERENCIA. 


\title{
LA CONFERENCIA DE PRESIDENTES: ORIGEN, EVOLUCIÓN Y PERSPECTIVAS DE REFORMA
}

\author{
JAVIER TAJADURA TEJADA ${ }^{1}$
}

\section{INTRODUCCIÓN}

A la hora de hacer un balance de los cuarenta años de nuestra constitución territorial, cabe destacar como aspectos negativos, la elevada conflictividad entre el poder central y los poderes territoriales, y el escaso desarrollo de las instituciones de cooperación.

Desde esta óptica, podemos señalar como un hito significativo y positivo en la evolución del Estado Autonómico, la creación, el 28 de octubre de 2004, por iniciativa del entonces Presidente del Gobierno, J. L. Rodríguez Zapatero, de la primera Conferencia de Presidentes que reunió al jefe de Gobierno con sus homólogos de las 17 Comunidades Autónomas y dos Ciudades Autónomas. La creación de la Conferencia respondió a una necesidad objetiva del sistema. La de que los Presidentes —el del gobierno de la Nación y los de las CC. AA— intercambiasen puntos de vista, iniciativas y propuestas, y debatieran sobre los grandes problemas que, por afectar a todos (Comunidades y Estado), requieren una respuesta conjunta y coordinada, así como sobre las reformas que el Estado Autonómico reclama.

Esta institución, de una u otra forma, está presente en la mayor parte de los Estados federales o compuestos situados en la órbita de lo que se ha dado en llamar federalismo cooperativo. Ahora bien, en España, a diferencia de otros Estados compuestos, la Conferencia no estaba prevista en nuestro ordenamiento jurídico. Esa laguna legal se ha cubierto con lo dispuesto en el artículo 146 de la ley 49/2015, de 1 de octubre, de Régimen Jurídico del Sector Público:

«1. La Conferencia de Presidentes es un órgano de cooperación multilateral entre el Gobierno de la Nación y los respectivos Gobiernos de las Comunidades Autónomas y está formada por el Presidente del Gobierno, que la preside, y por los Presidentes de las Comunidades Autónomas y de las Ciudades de Ceuta y Me-

${ }^{1}$ Catedrático (A.) de Derecho Constitucional. Departamento de Derecho Constitucional e Historia de la Teoría Política. Facultad de CC. Sociales y de la Comunicación de la UPV-EHU. Barrio de Sarriena s/n 48940 LEIOA. E mail: javier.tajadura@ehu.eus 
lilla. 2.La Conferencia de Presidentes tiene por objeto la deliberación de asuntos y la adopción de acuerdos de interés para el Estado y las Comunidades Autónomas, estando asistida para la preparación de sus reuniones por un Comité preparatorio del que forman parte un Ministro del Gobierno, que lo preside, y un Consejero de cada Comunidad Autónoma».

Ahora bien, la relevancia política de esta institución y las funciones constitucionales de integración que desempeña aconsejan dotarle de un mayor grado de formalización e incluirla en el Texto constitucional en el momento en que se aborde la necesaria reforma de la Constitución territorial.

En este contexto, creo oportuno dedicar mi contribución a este número monográfico que, a iniciativa de mi maestro el profesor Torres del Moral está dedicado a conmemorar el cuadragésimo aniversario de la Constitución, a examinar el diseño jurídico de una institución fundamental para el correcto funcionamiento de un estado políticamente descentralizado.

En la I Conferencia, 28 de octubre de 2004, se abordaron dos cuestiones fundamentales: la participación autonómica en asuntos europeos, y la financiación de la asistencia sanitaria. Desde entonces y hasta hoy se han celebrado cinco Conferencias más. En la II Conferencia, 10 de septiembre de 2005, se alcanzó un acuerdo sobre la financiación sanitaria. La III Conferencia, 11 de enero de 2007, abordó el tema de la investigación y el desarrollo tecnológico, y en ella se acordó la creación de Conferencias sectoriales sobre Agua e Inmigración y la formación de un grupo de trabajo para elaborar el reglamento interno de la misma. Reglamento que fue aprobado en la IV Conferencia ${ }^{2}, 14$ de diciembre de 2009, junto con sendas declaraciones sobre las prioridades de España para la presidencia del Consejo de la UE en 2010 y sobre un plan de medidas a adoptar contra la violencia de género.

La V Conferencia, 2 de octubre de 2012, primera del gobierno de Mariano, Rajoy aprobó una declaración sobre la estabilidad fiscal y la situación económica y laboral de España. Pasaron años sin que la Conferencia volviera a reunirse, hasta que, finalmente, la VI Conferencia tuvo lugar el 17 de enero de 2017. Conferencia en que, entre otras cosas, y para evitar que volvieran a pasar cinco años sin reunirse, se acordó nuevamente que la convocatoria fuera anual ${ }^{3}$. Se modificó el reglamento de la Conferencia para atribuir a la comisión preparatoria funciones de evaluación del cumplimiento de lo acordado ${ }^{4} \mathrm{y}$, desde un punto de vista sustantivo, se rubricaron 11 acuerdos, un record en su corta historia: un acuerdo

${ }^{2}$ Orden TER/3409/2009, de 18 de diciembre, por la que se dispone la publicación del reglamento interno de la Conferencia de Presidentes. BOE, núm. 395. 19 de diciembre de 2009.

3 El Reglamento de 2009 ya preveía la convocatoria anual.

4 Orden PRA/265/2017, de 23 de marzo, por la que se publica el Acuerdo por el que se modifica el reglamento interno de la Conferencia de Presidentes. BOE núm. 73, 27 de marzo de 2017. 
sobre la Reforma de la financiación autonómica ${ }^{5}$, una Estrategia Nacional para el reto demográfico ${ }^{6}$, un Pacto social y político por la educación ${ }^{7}$, un acuerdo en materia de Protección Civil ${ }^{8}$, una declaración sobre la unidad de mercado y movilidad ${ }^{9}$, un acuerdo sobre la tarjeta social ${ }^{10}$, y otro sobre el bono social ${ }^{11}$, una declaración sobre la Participación en asuntos UE ${ }^{12}$, un pacto sobre las políticas de empleo ${ }^{13}$ y otro contra la violencia de género ${ }^{14}$. El éxito de la Conferencia se vio empañado por el hecho de que fue la primera a la que no concurrieron todos los presidentes. Faltaron los de las Comunidades Autónomas de Cataluña y el País Vasco. En todo caso el presidente de esta última anunció, con posterioridad, que el Gobierno Vasco participaría en las comisiones y grupos de trabajo creados por la Conferencia.

Por lo que se refiere a su regulación, esta se limita, a fecha de hoy, a su Reglamento interno aprobado en 2009 y modificado en 2017 y a lo dispuesto en el art. 146 de la ley 49/2015.

5 En un mes, una comisión de expertos empezará a trabajar. También, en el plazo de un mes, otra comisión estudiará el sistema de dependencia. Asimismo, el grupo de expertos tendrá dos líneas específicas de trabajo, el gasto en sanidad y la corresponsabilidad fiscal de las autonomías. Simultáneamente se emprenderá la reforma de la financiación local

${ }^{6}$ Se alerta de que, en 2031, España habrá perdido medio millón de habitantes. La dimensión del cambio demanda la cooperación de todas las administraciones públicas en la elaboración este año de una estrategia para afrontar la nueva situación.

7 El acuerdo insta a la Comisión General de Comunidades Autónomas del Senado a celebrar un debate monográfico, con asistencia de los consejeros del ramo e incorporar sus conclusiones a la subcomisión del Congreso.

${ }^{8}$ El Gobierno y las CCAA crearán con representantes de cada una, y antes del 31 de marzo, el Consejo Nacional de Protección Civil para mejorar la coordinación ante catástrofes.

9 Se favorecerá que funcionarios, especialmente de alto nivel, puedan moverse a otras comunidades. También se ajustará la oferta de empleo público en sanidad, educación, policía o servicios de emergencia conforme a las especiales necesidades de cada comunidad. Y la tasa de reposición se flexibilizará en ámbitos prioritarios respetando las reglas de gasto. Se analizará la situación de los interinos para dar estabilidad a estos trabajadores

10 Se impulsa la creación de una tarjeta que permita saber qué ayudas reciben los ciudadanos.

11 Para hacer partícipes a las CCAA del decreto-ley aprobado hace unas semanas para evitar cortes eléctricos en familias con pocos recursos.

${ }^{12}$ Se convocará en el primer trimestre del año la Conferencia para Asuntos Relacionados con la Unión Europea. Se estudiará si se cambia su reglamento para dar mayor agilidad a la toma de decisiones. Se persigue que las CCAA intervengan más en las posiciones que defenderá España en la UE, incluyendo la negociación de fondos. Se incluirá la elaboración de un plan de ayuda de emergencia a refugiados.

13 Se insta a la modernización de los servicios de empleo, a dotar de mayor eficiencia a las políticas activas y a seguir avanzando en la formación profesional. El estímulo de la Garantía Juvenil es otro punto, al igual que la protección de parados mayores de 45 años.

${ }^{14} \mathrm{La}$ Conferencia insta a la celebración de una sesión monográfica sobre esta materia, con intervención de los consejeros competentes, para que las conclusiones formen parte del estudio de la subcomisión creada en el Congreso. 


\section{LAS CONFERENCIAS DE PRESIDENTES Y EL DESARROLLO DEL PRINCIPIO CONSTITUCIONAL DE COOPERACIÓN}

En un sugerente ensayo sobre las reformas territoriales, el profesor Ortega planteaba con acierto la necesidad de superar el actual título VIII de la Constitución: «Debemos pasar de un Título VIII de creación del modelo a un Título VIII de funcionamiento del modelo» ${ }^{15}$. En ese nuevo Título debe ocupar un lugar central el principio de cooperación, y ello porque el funcionamiento eficaz del Estado sólo podrá lograrse en la medida en que se articulen mecanismos y procedimientos que canalicen la cooperación entre las distintas instancias territoriales del poder, y en que exista una voluntad real de cooperación entre ellas.

La consolidación y perfeccionamiento de nuestro Estado Autonómico exige llevar a cabo unas reformas tendentes a su modernización: «Una de las claves de esta modernización exigida y que lentamente se va implantando — escribe Ortega - es la perspectiva de un resultado conjunto de la actuación de todas las instancias políticas implicadas en un asunto. El resultado social de las políticas públicas en un modelo descentralizado es siempre producto de una actuación plural. Por ello la nueva reforma debe incidir esencialmente, no tanto en el volumen competencial, sino en las formas de este ejercicio competencial. Se deben trasladar a la Constitución los principios de una actuación cooperativa y solidaria» ${ }^{16}$.

Desde esta perspectiva, que comparto plenamente, la reforma de nuestra constitución territorial debería tener un doble objeto: por un lado, proceder al cierre del modelo estableciendo en el texto constitucional un sistema de reparto competencial claro, para el que la Constitución de la República Federal de Alemania sería un buen modelo a seguir; y, por otro, desarrollar el principio constitucional de cooperación, mediante la inclusión de los oportunos instrumentos y procedimientos que sirvan de cauce de relaciones cooperativas entre las distintas instancias territoriales de poder ${ }^{17}$.

Desde un punto de vista institucional, la doctrina destaca como el Senado y la Conferencia de Presidentes se configuran como los pilares fundamentales del principio de cooperación. Ahora bien, — frente a la importancia que en el debate político se atribuye a la reforma del Senado ${ }^{18}$ — debemos destacar que una de las enseñanzas del federalismo comparado es que los órganos de cooperación intergubernamental ocupan hoy la posición central que en este aspecto pudo corresponder en el pasado a las Cámaras Altas. Así lo ha puesto de manifiesto el profesor Eliseo Aja, gran experto

15 Ortega, L. (2005): Reforma Constitucional y Reforma Estatutaria, Civitas, Madrid, pág. 49.

16 Ortega, L. (2005): Reforma Constitucional y Reforma Estatutaria, ob. cit., págs. 49 y 50.

17 Tajadura, J. (2010): El principio de cooperación en el estado Autonómico. El Estado Autonómico como Estado Federal cooperativo, tercera edición renovada y aumentada, Comares, Granada.

18 Una excelente exposición sobre el verdadero significado de las segundas cámaras, en SAENZ, E. (2014): Desmontando mitos sobre el Estado autonómico, Marcial Pons, Madrid. Págs. 47 y ss. Sobre la relación entre el Senado y la Conferencia de presidentes, el interesante estudio de Reviriego, F. (2006): «El Senado y la Conferencia de Presidentes», Teoría y Realidad Constitucional, núm. 17. 
en ambos temas: «En todos los federalismos existen instituciones importantes donde se discuten los problemas comunes a los diferentes Estados o länder y se buscan las soluciones. En el pasado (y aun hoy en Alemania) esa instancia fue el Senado, pero (...) en Estados Unidos o Suiza el Senado ya no cumple esa función y ha sido sustituido por otros mecanismos de relación directa entre los gobiernos, que se integran en las llamadas relaciones intergubernamentales» ${ }^{19}$. Mecanismos entre los que ocupan un lugar destacado las Conferencias Sectoriales y las Conferencias de Presidentes.

En suma, es una opinión doctrinal generalizada, la necesidad de fortalecer estos instrumentos cooperativos ${ }^{20}$. Solo por ofuscación o por dolo se puede rechazar la oportunidad y la conveniencia de consolidar las Conferencias de Presidentes. Se trata de una institución que puede contribuir a resolver los cuatro grandes problemas que el Estado Autonómico ha puesto de manifiesto en las últimas cuatro décadas, a saber, su excesiva bilateralidad, su excesiva conflictividad, la deficiente participación autonómica en temas que les afecten (fundamentalmente, política europea) y la inexistente cooperación horizontal entre Comunidades Autónomas.

La conflictividad solo se atenuará mediante una reforma constitucional del orden de distribución de competencias que precise el significado y alcance de categorías como «competencia exclusiva» y «competencia concurrente» ${ }^{21}$. Pero, junto a esta reforma, la inclusión de instituciones de cooperación — como las que nos ocupanredundará también en un descenso de la conflictividad global.

\section{NATURALEZA Y CARACTERES DE LA INSTITUCIÓN}

Como rasgos definitorios de la Conferencia de Presidentes podemos señalar los siguientes:

a) En primer lugar, la justificación de la institución reside en las funciones que está llamada a desempeñar y que sólo ella puede cumplir ${ }^{22}$. Ante todo, configurar-

19 AJA, E. (1999): El Estado Autonómico. Federalismo y Hechos diferenciales. Alianza Editorial, Madrid. Págs. 198-199; (2014): Estado Autonómico y Reforma Federal, Alianza Editorial, Madrid, págs. 220 y ss.

20 Ridaura Martinez, M.J. (2009): Relaciones intergubernamentales Estado-Comunidades Autónomas, Tirant lo Blanch, Valencia. RuIZ GonZALEZ, J. G. (2012): «La cooperación intergubernamental en el Estado Autonómico: situación y perspectivas», Revista d'Estudis Autonòmics i Federals, núm. 15.

${ }^{21}$ Sobre el inextricable universo de las competencias que caracteriza al Estado Autonómico actual, MUÑOZ MACHADO, S. (2012): Informe sobre España. Repensar el Estado o destruirlo, Crítica, Barcelona. Págs. 99-171.

${ }^{22}$ En este sentido, el art. 2 de su Reglamento le atribuye tres bloques de funciones. «1. Debatir sobre las grandes directrices de las políticas públicas, sectoriales y territoriales de ámbito estatal, sobre las actuaciones conjuntas de carácter estratégico, y sobre los asuntos de importancia relevante para el Estado de las Autonomías, que afecten a los ámbitos competenciales estatal y autonómico. 2. Potenciar las relaciones de cooperación del Estado con las Comunidades Autónomas. 3. Impulsar y orientar los trabajos de las Conferencias Sectoriales y de otros órganos multilaterales de cooperación». 
se como un foro de encuentro y diálogo entre todos los Presidentes. Foro que permita la discusión sobre los grandes problemas de Estado ${ }^{23}$, incluidos los relativos al propio modelo de Estado Autonómico ${ }^{24}$; foro que permita la superación de situaciones de bloqueo y la resolución de los conflictos políticos que puedan surgir en las relaciones entre el poder central y los territoriales; foro que sirva también para canalizar la cooperación entre las Comunidades Autónomas para la defensa de las propias competencias mediante un mejor ejercicio de las mismas, y que permita incluso excluir la intervención estatal mediante un ejercicio conjunto de las competencias autonómicas.

b) En segundo lugar, - y como consecuencia de esa diversidad de funciones- la Conferencia debería presentar dos formaciones, una horizontal integrada exclusivamente por los Presidentes autonómicos, y otra vertical que incluya la presencia del Presidente del Gobierno. La configuración vertical de la Conferencia resulta indispensable siempre que se vayan a discutir cuestiones de Estado. Carece, sin embargo, de sentido cuando lo que se va a tratar es la defensa de las competencias autonómicas a través de un ejercicio mancomunado de las mismas.

c) En tercer lugar, un rasgo definitorio esencial de esta institución es su naturaleza estrictamente política. Esto es, nos encontramos ante un órgano político cuya función esencial va a ser el debate y la deliberación de problemas con el objeto de lograr acuerdos sobre los mismos, pero no la adopción de decisiones jurídicamente vinculantes. La Conferencia alumbrará acuerdos políticos cuya traducción jurídica dependerá del sistema de reparto competencial constitucionalmente establecido.

d) En cuarto lugar, la Conferencia como tal no es titular de competencia alguna y por ello su establecimiento en nada incide ni afecta al sistema de distribución de competencias constitucionalmente establecido.

e) Como consecuencia de que las instituciones que nos ocupan no son titulares de competencias en sentido estricto, el establecimiento de la Conferencia de Presidentes —en su formación vertical — ha sido posible al margen de cualquier previsión legal al respecto. La ley 49/2015 ha cubierto esa laguna.

${ }^{23}$ Problemas que, aunque afectan a materias de competencia estatal, indirectamente acaban por afectar también a las Comunidades: política de inmigración, planificación de infraestructuras de interés general, prevención de incendios, lucha contra el crimen organizado.

${ }^{24}$ Entre estos podemos citar: la financiación autonómica, la aprobación de Leyes básicas o de Leyes de Delegación, la reforma de los Estatutos de Autonomía, la aprobación de planes estatales de coordinación o de acciones conjuntas con las Comunidades Autónomas, o la forma de participación de éstas en los asuntos europeos. 
f) La regulación del funcionamiento de la Conferencia puede y debe ser muy flexible. En la medida en que no puede adoptar actos jurídicos vinculantes y, en consecuencia, impugnables, carece de sentido el establecimiento de excesivos formalismos que encorseten su actuación. Pero es precisa una formalización que garantice su existencia y funcionamiento y que impida que — como ha ocurrido- puedan transcurrir 4 años sin que se convoque y reúna.

g) Su funcionamiento debe tener por norte la búsqueda del consenso. En la medida en que la función básica de la Conferencia es el logro de acuerdos, y no la adopción de actos jurídicos, resulta claro que la eficacia de aquellos es incompatible con el principio de mayoría ${ }^{25}$. El acuerdo debe ser fruto del consenso y no de la imposición de la mayoría sobre la minoría. Esto, evidentemente, resulta más fácil decirlo que llevarlo a la práctica. El principio mayoritario tiene su lugar en otros órganos competentes del Estado y de las Comunidades. En todo caso, establecida la necesidad del consenso hay que huir de lo que acertadamente se ha denominado «trampa del consenso» y de la consiguiente parálisis del Estado ${ }^{26}$. En nuestro ordenamiento, el Estado dispone de medios para, en todo caso, afrontar y resolver los problemas y las grandes cuestiones que le afecten.

h) Las Conferencias se sitúan en la cúspide de un sistema piramidal de relaciones cooperativas. Sistema integrado por las Conferencias Sectoriales ${ }^{27}$ (de Ministros y Consejeros) y los grupos de trabajo integrados por altos funcionarios de las distintas administraciones. Desde esta óptica son el «máximo» órgano de cooperación y no uno más como parece sugerir la redacción del artículo 146 de la ley $49 / 2015^{28}$.

Una vez enunciadas estas ocho notas que van a determinar el régimen jurídico de la Conferencia, y su lugar en el Estado Autonómico, procede examinar alguna de ellas con mayor detalle.

${ }^{25}$ Los profesores Bocanegra y Huergo en una meritoria monografía sobre esta institución, advierten expresamente de «la necesidad de sostener (la Conferencia) en la búsqueda de consensos, mucho más que en la adopción de acuerdos mayoritarios, que con toda probabilidad arrastrarían irremediablemente al fracaso de la Conferencia». Bocanegra, R., y Huergo, A. (2005), La Conferencia de Presidentes, Iustel, Madrid. Pág. 69.

${ }_{26}$ Sobre este tema en relación con el federalismo alemán, DARnSTADT, T. (2005): La trampa del consenso, Trotta, Madrid. Con un brillante Estudio Preliminar del profesor Sosa Wagner.

${ }_{27}$ Sobre las Conferencias Sectoriales, Duque Villanueva, J. C. (2007): «Las Conferencias Sectoriales», Revista Española de Derecho Constitucional, núm. 79; Tajadura, J. (2010): «Federalismo cooperativo y conferencias sectoriales: marco normativo y propuestas de reforma», Revista Jurídica de Navarra, núm. 49.

${ }^{28}$ La Ley se refiere a la Conferencia como «un órgano de cooperación», al mismo nivel que los demás, mientras que su Reglamento de 2009 la califica como el «máximo órgano de cooperación política», subrayando su posición de primacía respecto a los demás (Conferencias Sectoriales). 


\section{LA DOBLE CONFIGURACIÓN (HORIZONTAL Y VERTICAL) DE LA CONFERENCIA DE PRESIDENTES}

Varias, y muy distintas, son las funciones que la Conferencia de Presidentes debe cumplir. Esta puede y debe ser tanto un instrumento de participación en competencias estatales como de defensa de las propias competencias autonómicas. Ahora bien, nos encontramos con que para desempeñar con éxito esas tareas, en unos casos resulta imprescindible la presencia del Presidente del Gobierno mientras que en otros, dicha presencia resulta disfuncional.

Concebida la Conferencia como un instrumento que permite a los Presidentes Autonómicos pronunciarse sobre los grandes problemas y cuestiones que afectan al Estado (la problemática de la inmigración en sentido amplio, la incidencia del cambio climático, el envejecimiento de la población...etc), entre los cuales destacan los relacionados con el propio modelo de Estado Autonómico, resulta evidente la necesidad de configurarla de forma vertical, esto es, como Conferencia del Presidente del Gobierno con los Presidentes Autonómicos. Dos razones avalan esta conclusión:

a) En primer lugar, porque sin la participación en ella del Presidente del Gobierno, ningún interés tendrían los Presidentes Autonómicos en expresar de forma colectiva su opinión sobre los mencionados problemas. En la medida en que los temas abordados son competencia de los poderes centrales, el interés de los Presidentes Autonómicos consiste, precisamente, en que el Presidente del Gobierno les escuche, para en su caso, tomar las decisiones pertinentes.

b) En segundo lugar, precisamente porque los temas a discutir afectan directamente a competencias estatales, esto es, no autonómicas, no parece legítimo que sean abordados exclusivamente por los Presidentes Autonómicos. En resumen, la exclusión del Presidente del Gobierno de la Conferencia de Presidentes cuando esta desempeña las funciones mencionadas convertiría a estas en inútiles, desde un punto de vista práctico, y, desde un punto de vista teórico, arrojaría dudas sobre su compatibilidad con el principio de lealtad federal.

Por el contrario, cuando la Conferencia cumple una función de defensa y promoción de las propias competencias autonómicas (no de participación en las competencias estatales), comparando experiencias o debatiendo iniciativas comunes, la presencia en ella del Presidente del Gobierno resulta claramente disfuncional. Y ello también por dos razones fácilmente comprensibles:

a) En primer lugar, porque dificultaría notablemente el debate y deliberación de los temas en la medida en que será él, normalmente, el destinatario de esas reclamaciones conjuntas. Resultaría difícil para aquellos Presidentes Autonómicos pertenecientes al mismo partido que el Presidente del Gobierno, hacer un frente común con 
Presidentes Autonómicos de otros partidos en su presencia. La adopción de este tipo de acuerdos políticos entre los Presidentes Autonómicos, excluye la presencia del Presidente del Gobierno en la Conferencia.

b) En segundo lugar, la presencia del Presidente del Gobierno carece por completo de sentido en todos aquellos casos en que el objetivo pretendido por la Conferencia es precisamente excluir la intervención estatal, esto es «bloquear preventivamente, la intervención estatal de coordinación (impuesta desde arriba) sustituyéndola por una flexible y voluntaria autocoordinación» ${ }^{29}$.

No cabe, por tanto, plantear la institucionalización de la Conferencia en los términos de una alternativa entre su formación horizontal o vertical. Según que tareas vaya a desempeñar, ambas son necesarias.

En todo caso, la presencia y participación del Presidente del Gobierno en determinadas reuniones de la Conferencia y su exclusión en otras, nos exige precisar si bajo la denominación Conferencia de Presidentes nos referimos a una institución única o a dos diferentes, y cuál es, en su caso, la posición del Presidente del Gobierno en ella (un miembro nato que en ocasiones se abstiene de participar o por el contrario alguien que, no siendo miembro de la Conferencia, es invitado a participar en ella en determinadas ocasiones).

En nuestra opinión, creemos que el modelo alemán que distingue las reuniones del Canciller y los Presidentes de los Länder, de las que estos últimos mantienen de forma separada, resulta más apropiado a las necesidades que el principio de cooperación plantea en el Estado Autonómico español. La posición del Presidente del Gobierno no puede encajar adecuadamente en una configuración única de la institución. Y ello porque no podemos considerarle un mero invitado al que se le permite acudir a unas sesiones y no a otras. $\mathrm{Y}$ porque, como hemos visto, tampoco parece funcional convertirlo en miembro nato de la Conferencia, habida cuenta que ello significaría que la posibilidad de celebrar una Conferencia horizontal, dependería en todo caso, de la decisión del Presidente del Gobierno de no acudir. Dicho con otras palabras, ello sería tanto como otorgarle un derecho de veto para la celebración de aquella.

Nos encontramos, por tanto, con dos instituciones, de composición distinta, y llamadas a desempeñar tareas también diferentes. Aunque en este trabajo nos cen-

29 «Esto no quiere decir —añade el profesor Bocanegra, con palabras que compartimos plenamente- que siempre carezca de sentido la presencia de representantes del Estado en las comisiones o grupos de trabajo de cooperación entre las Comunidades Autónomas. En muchos casos, esa presencia será muy útil para aportar conocimientos o experiencias, en especial porque la actuación autonómica, aun en ámbitos de su estricta competencia, nunca está completamente aislada de la estatal, y suele ser perfectamente inútil ignorarla. Se trataría, sin embargo, de una presencia lateral, a título estricto de información y colaboración, muy distinta al papel que a los Ministros corresponde en las Conferencias Sectoriales al uso». Bocanegra, R., y Huergo, A., La Conferencia de Presidentes, ob.cit. ..., pág. 78. 
tramos en la Conferencia vertical, debemos señalar que a falta de Conferencias de Presidentes Autonómicos —aunque han tenido menor eco mediático- también han surgido al margen de toda previsión normativa unos encuentros de Gobiernos Autonómicos. En 2008 por iniciativa del gobierno de Aragón se celebraron en Zaragoza los Primeros Encuentros de CC.AA. Desde entonces, se han celebrado ocho Encuentros, en los que se han aprobado seis declaraciones y se han acordado once convenios o protocolos ${ }^{30}$. Las Comunidades integrantes de los Encuentros - todas excepto la Comunidad Autónoma del País Vasco- acordaron, en el VIII Encuentro, celebrado en Santiago de Compostela el 25 de octubre de 2010, la creación de la Conferencia de los Gobiernos de las Comunidades Autónomas, aprobando en ese mismo acto sus Normas de organización y funcionamiento ${ }^{31}$. Dicho esto, en las páginas que siguen vamos a ocuparnos, básicamente, del marco normativo de la conferencia vertical

\section{LA COMPOSICIÓN DE LA CONFERENCIA Y LA OBLIGACIÓN DE ASISTIR}

La composición de la Conferencia viene determinada por lo dispuesto en el art. 146 de la Ley 49/2015 según el cual aquella «está formada por el Presidente del Gobierno, que la preside, y por los Presidentes de las Comunidades Autónomas y de las Ciudades de Ceuta y Melilla». El artículo 3 del Reglamento interno incluye el carácter «indelegable» de la participación. ${ }^{32}$.

La condición de miembro de las Conferencias corresponde exclusivamente al Presidente del Gobierno y a los Presidentes Autonómicos. La propia naturaleza de la institución (órgano político de cooperación al máximo nivel político) otorga a la condición de miembro de la Conferencia un carácter indelegable. Como han recordado los profesores Bocanegra y Huergo: «Sólo los Presidentes se encuentran, por su posición política, en condiciones de manifestar la posición de la Administración a la que representan y de hacerlo como punto de partida de acuerdos y negociaciones. Es

30 De Pedro Bonet, X. (2011): «La Conferencia de los Gobiernos de las Comunidades Autónomas», Informe Comunidades Autónomas 2010, Instituto de Derecho Público, Barcelona, 2011, pp. 108-112.

31 Sobre este proceso, el interesante estudio publicado en estas mismas páginas, GALVEZ, L.A. y RUIZ, J.G. (2013): «Estado autonómico, cooperación intergubernamental y Conferencia de Presidentes» en Revista de Derecho Político, núm. 86, enero-abril 2013, págs. 229-254

32 «1. La Conferencia de Presidentes estará compuesta por el Presidente del Gobierno, que la preside, y los Presidentes de las Comunidades Autónomas y de las Ciudades de Ceuta y Melilla. 2. Actuará como Secretario el Ministro competente en materia de cooperación territorial que asistirá, a estos efectos, a las reuniones. 3. La asistencia a las reuniones de la Conferencia es indelegable y no cabe la sustitución, salvo en los casos en los que, de acuerdo con lo previsto en las respectivas normativas autonómicas, un Consejero ejerza temporalmente las funciones de Presidente Autonómico. 4. Cuando el orden del día lo aconseje, los presidentes podrán acudir acompañados, en calidad de asesor, por un miembro de su respectivo Gobierno» 
evidente, tanto desde una perspectiva jurídico-formal como desde la propia realidad política, que los Presidentes constituyen la figura central de la Comunidad Autónoma, dotados de una legitimidad democrática indiscutible, que se refuerza en el actual sistema electoral de listas cerradas y bloqueadas (en el que, de hecho, los votantes se movilizan en las elecciones autonómicas por los candidatos a la Presidencia, que encabezan las listas electorales, más que por el resto de sus componentes), sin comparación alguna con la del resto de los miembros del Consejo de Gobierno, que son nombrados por él» ${ }^{33}$.

La doctrina ha visto en esa preeminencia política del Presidente de la Comunidad Autónoma, uno de los rasgos definitorios del sistema institucional de las Comunidades. En este sentido, el profesor Torres del Moral ha escrito: «Realizado el nombramiento del Presidente, que debe ser miembro de la Asamblea Legislativa, éste designa y cesa libremente a los restantes miembros del Gobierno autonómico, sin intervención del Parlamento. Aquella investidura personal y esta facultad discrecional colocan al Presidente en una posición de neta preeminencia sobre el resto del Gobierno, correspondiéndole la orientación política general de la Comunidad Autónoma. Preeminencia que la propia Constitución establece al disponer que el Presidente dirige el Consejo de Gobierno. Los Estatutos y las leyes autonómicas la han acentuado al centrar en él la responsabilidad política del Gobierno ante el Parlamento y concederle la facultad de disolución de éste; todo ello en términos parecidos a los utilizados por la Constitución respecto del Presidente del Gobierno Central» ${ }^{34}$. Sólo quien ostenta esa facultad de «orientación política general de la Comunidad Autónoma» está en condiciones de poder participar en la Conferencia. Por esa razón, dicha facultad ha de considerarse indelegable.

Admitir la posibilidad de que los Presidentes Autonómicos deleguen en otros miembros de sus respectivos gobiernos la participación en la Conferencia impediría distinguir a esta de los otros instrumentos cooperativos actualmente insistentes (Conferencias Sectoriales). Igualmente, impediría configurar la Conferencia como órgano político de cooperación al máximo nivel, pues esa «supremacía política» sólo la garantiza la presencia en la Conferencia de los Presidentes de Gobierno. A mayor abundamiento, esa posibilidad daría lugar a una composición desigual de la Conferencia, a la que unos Presidentes acudirían y otros se limitarían a enviar delegados. A la larga, y con el fin de no devaluar su propia presencia, todos los Presidentes optarían por delegar su participación, condenando de ese modo a la Conferencia al más absoluto de los fracasos.

Por todo lo anterior, es preciso insistir en que, en la Conferencia no puede ser aceptada una representación de menor rango que el de Presidente. Y esto es predicable, obviamente, tanto respecto a los Presidentes Autonómicos como respecto al

33 Bocanegra, R., y Huergo, A., La Conferencia de Presidentes, ob.cit, Pág. 93.

34 Torres del Moral, A. (2005): Principios de Derecho Constitucional Español, Servicio de Publicaciones de la Facultad de Derecho de la Universidad Complutense, 5. a edición, Madrid, Tomo II, pág. 310. 
Presidente del Gobierno, y tanto para la configuración vertical como para la horizontal de la Conferencia ${ }^{35}$.

Los profesores Bocanegra y Huergo señalan que «podría preverse (...) la posibilidad de que un Presidente delegue en otro su representación, en caso de ausencia justificada (como ocurre con el Consejo Europeo)» ${ }^{36}$. Si bien es cierto que esta previsión resultaría compatible con el principio del máximo rango de la representación, que se ejercería por delegación por otro miembro de la Conferencia, esto es, por otro Presidente Autonómico, creo que debe ser descartada. Esa delegación puede plantear dudas de constitucionalidad. Aunque la Conferencia no adopte actos jurídicos sino acuerdos políticos, resulta harto problemático que el Presidente de una Comunidad pueda comprometer políticamente a otra distinta, aun con una delegación expresa del Presidente de esta última. Dicho con otras palabras, en la Conferencia, los Presidentes Autonómicos actúan como titulares de una competencia de «orientación política general de la Comunidad», que emana de su designación por una mayoría parlamentaria elegida por el cuerpo electoral de la Comunidad Autónoma. Esa facultad por la propia lógica del sistema debería configurarse como indelegable. No puede admitirse, por ejemplo, que el Presidente de Murcia represente a la Comunidad Autónoma de Andalucía, porque se rompe (aunque no formalmente, sí materialmente) la cadena de la legitimidad democrática.

En los supuestos de ausencias motivadas por causas justificadas y relevantes resulta preferible prever que la reunión sea pospuesta. Siempre resultará mejor posponer la reunión que admitir cualquier tipo de delegación o sustitución. Así lo admiten también los autores citados. No cabría admitir sustituciones por otros compromisos políticos, ni por viajes de ningun tipo, oficiales o privados. La sustitución sólo resultaría aceptable por causa de enfermedad u otras circunstancias que impidieran de hecho al Presidente Autonómico el ejercicio de su función. En esos casos, acudiría el Vicepresidente que si podría legitimamente comprometer a su Comunidad, y ejercería en esas circunstancias las funciones presidenciales.

Cuestión relacionada con ella es la posibilidad de que a la Conferencia asistan los Presidentes «en funciones» (no los Vicepresidentes que ejercen de Presidentes en funciones, sino los Presidentes cuyo mandato ha concluido). En la medida en que las últimas reformas estatutarias conducen a la desaparición de una de las diferencias institucionales básicas existentes entre las Comunidades creadas por el artículo 143 CE y las alumbradas en virtud del artículo 151: la existencia para las primeras de una

35 Conviene precisar que el hecho de que la presencia de los Presidentes sea absolutamente necesaria e imprescindible, no quiere decir que sea exclusiva. Esto es, el Presidente de la Comunidad Autónoma no puede delegar su participación en nadie, pero sí que puede ir acompañado de otras personas (miembros o no de su Gobierno) para que le apoyen en la preparación de los temas. Esta es una cuestión que también habría que prever legalmente estableciendo un número máximo de acompañantes, número que no debiera exceder de 3, para no convertir la Conferencia en una Asamblea excesivamente tumultuosa.

36 Bocanegra, R., y Huergo, A., La Conferencia de Presidentes, ob.cit, Pág. 94. 
fecha electoral común para la renovación de sus Asambleas Legislativas, será frecuente que algún Presidente Autonómico lo sea en funciones.

En esos casos también resulta preferible posponer la conferencia. Ello resulta lógico en la medida en que, si los gobiernos en funciones ven limitada su actuación a los asuntos de trámite, evidente resulta que la participación activa en una Conferencia de Presidentes nunca podrá recibir tal calificación ${ }^{37}$. En todo caso, lo que sí debería quedar claro en la regulación de la Conferencia es que por lo que se refiere a la Presidencia del Gobierno de España, debe excluirse la celebración de Conferencias, estando aquella en funciones.

Ahora bien, si establecemos una periodicidad anual de la misma — como se acordó en 2009 y se ha confirmado en 2017 — no siempre resultará compatible el aplazamiento de la reunión con el cumplimiento de su periodicidad ordinaria. En esos casos, debería admitirse la presencia de los Presidentes Autonómicos (reitero, no del Gobierno central) en funciones. En todo caso, dichos presidentes actuarían en ella con las limitaciones inherentes a su condición ${ }^{38}$. Limitaciones notablemente mayores en aquellos casos en que sea previsible su sustitución por un presidente perteneciente a una fuerza política distinta.

La cuestión relativa a la obligación de asistir a las Conferencias es, junto con el procedimiento para la adopción de acuerdos, una de las cuestiones más problemáticas de la institución que nos ocupa.

Si como hemos visto las Conferencias se configuran como órganos políticos, sin competencias propias y sin facultades para la adopción de actos jurídicos vinculantes, cuyo principio básico es la búsqueda de acuerdos y el logro de amplios consensos sobre problemas generales del Estado, no parece posible introducir en su régimen jurídico el elemento coactivo, esto es la obligatoriedad, bien sea para asistir a las reuniones, bien sea para aceptar acuerdos adoptados por mayoría. La Ley 49/2015 y el Reglamento de la Conferencia guardan silencio sobre esta cuestión.

Siendo esto así, preciso es reconocer que, si verdaderamente la creación de las Conferencias se configura como la traducción jurídica de una voluntad política previa de desarrollar la cooperación vertical y horizontal en el Estado Autonómico, la cues-

${ }^{37}$ El tema debería ser regulado adecuadamente en la Ley. Lo dejo meramente apuntado, pero es evidente que no resultaría aceptable que un Presidente en funciones pudiera impedir el logro de un acuerdo consensuado por el resto de los participantes en la Conferencia. Sobre el Gobierno en funciones, véase la monografía del profesor Reviriego, REVIRIEGO, F. (2003): El gobierno cesante o en funciones en el ordenamiento constitucional español, BOE, Madrid. Como notas distintivas del mismo el autor subraya las siguientes: a)la transformación de su legitimidad al quebrar su vínculo fiduciario con el Parlamento; b) la brevedad de su mandato; c)la alteración de la capacidad de dirección política, quedando inhabilitado para desarrollar un programa conforme a criterios partidistas.

38 En última instancia y como ha señalado el profesor Torres del Moral, «si persiste la duda acerca de una determinada decisión, se debe de operar con arreglo a los criterios de corrección constitucional que invitan al Gobierno cesante a abstenerse de actuar, o bien a hacerlo del modo que comprometa lo menos posible la situación del Gobierno entrante (sede vacante nihil innovetur)». TORRES DEL MORAL, A.: Principios de Derecho Constitucional, ob.cit., Tomo II, pág. 181. 
tión no resultaría, en modo alguno, problemática. A ningún Presidente, en su sano juicio, se le ocurriría no asistir a las reuniones, salvo causas graves y justificadas. Los Presidentes Autonómicos no renunciarían a aprovechar la oportunidad que se les brinda de deliberar sobre los grandes temas de Estado. Ninguno incurriría en el error político que supondría quedar aislado y al margen de estos debates.

Ahora bien, a pesar de ello, la experiencia demuestra que, en ocasiones, determinadas Comunidades Autónomas renuncian a participar en este tipo de foros multilaterales de cooperación. Y ante este dato, inevitablemente surge la pregunta de si resultaría constitucionalmente aceptable establecer por Ley ordinaria la obligatoriedad de la asistencia. En la actualidad, el reglamento de funcionamiento prevé la inasistencia ${ }^{39}$ aunque cabe entender que se refiere a ausencias justificadas.

El tema es complejo, pero, en principio, creo que la previsión legal de la asistencia obligatoria no plantearía dudas de constitucionalidad. La obligación de asistir encuentra un fundamento constitucional indiscutible en el principio de lealtad federal. Es, por el contrario, la inasistencia, esto es, la ausencia injustificada de un Presidente Autonómico, la que carece, por completo, de apoyo constitucional. El principio de autonomía política no es absoluto. No cabe ampararse en él para negarse a participar en los instrumentos de cooperación interterritorial. Dicha conducta, cuyo único resultado es provocar un perjuicio al normal y eficaz funcionamiento del Estado, no puede ampararse nunca en el legítimo ejercicio de la autonomía sino en un claro uso abusivo de esta. Abuso del derecho proscrito por nuestro ordenamiento.

En este sentido hay que recordar que, a la VI Conferencia, no acudieron los presidentes de las CC. AA de Cataluña y del País Vasco. Y que, por lo que se refiere a la Conferencia horizontal, el Gobierno vasco tampoco participa en ellas.

Frente a estas conductas, cabe sostener que la participación en la Conferencia es una consecuencia del principio de lealtad, y que, en consecuencia, el establecimiento por ley de la obligación de asistir a la Conferencia no plantearía dudas de constitucionalidad puesto que emana directamente de la Constitución. Por ello mismo, el incumplimiento de esa obligación, con independencia de que se llegue o no a establecer por ley, es —en el momento actual— una violación de la Constitución. Con todo, la inclusión expresa de esa obligación en la Constitución despejaría definitivamente cualquier posible duda sobre esta cuestión.

En todo caso, el problema es que al incumplimiento de esa obligación es difícil atribuirle una sanción jurídica efectiva. Sólo cabe prever que el Tribunal Constitucional u otro declaren que se ha producido una violación del principio de cooperación. Pero los efectos de esta declaración (del Tribunal Constitucional o de un órgano jurisdiccional superior del orden contencioso-administrativo) — probablemente, aunque esto es algo que exigiría un estudio más detenido y una reflexión más profun-

39 Artículo 6. 2 del reglamento «Los acuerdos se adoptarán por consenso de todos los miembros presentes de la Conferencia, siempre que asistan dos tercios de los Presidentes Autonómicos (13)». 
da- no podrían ir mucho más allá de una severa desautorización del Gobierno Autonómico correspondiente.

Por otro lado, y desde un punto de vista eminentemente pragmático, ocurre que el principal perjudicado por ese incumplimiento es el que lo realiza: el Presidente Autonómico que siendo convocado decide no asistir. Esto es, su inasistencia determina que se vea privado de la posibilidad de ser oído y de participar en la deliberación de los grandes temas de Estado. Ahora bien, indiscutiblemente, con su inasistencia también está causando un perjuicio al resto de las Comunidades Autónomas (además de a la suya propia) y al Estado. Y ello porque elimina de raíz la posibilidad de alcanzar acuerdos y consensos globales sobre los temas tratados en la Conferencia. La inasistencia no es sino la traducción de un rechazo, no a un acuerdo concreto sobre un tema determinado (lo cual resulta legítimo), sino un rechazo a la posibilidad misma de lograr el acuerdo. Fácilmente se comprende, por tanto, que califiquemos una tal actitud como manifiestamente contraria al principio constitucional de cooperación y, por tanto, para decirlo con claridad y contundencia, como un comportamiento manifiestamente anticonstitucional.

\section{EL FUNCIONAMIENTO DE LAS CONFERENCIAS}

La designación del Presidente de la Conferencia reviste una gran importancia en la medida en que de él van a depender las convocatorias y los temas a tratar. La presidencia de la Conferencia vertical (del Presidente del Gobierno con los Presidentes Autonómicos) corresponde necesaria e inexcusablemente al Presidente del Gobierno. La posición constitucional que ocupa (en cuanto representante del interés general) resultaría incompatible con su presencia en un órgano colegiado presidido por un Presidente autonómico. Esta sola razón basta para rechazar cualquier posibilidad de que la Conferencia vertical sea presidida por un representante autonómico. Esta es la solución prevista en la Ley.

Al Presidente del Gobierno corresponde la convocatoria de las Conferencias ${ }^{40}$.

La Conferencia de Presidentes, en cuanto órgano político, no adopta actos jurídicos y, por ello, la institución del orden del día reviste en ella un significado

\footnotetext{
${ }^{40}$ Artículo 4 del reglamento: «1. La Conferencia de Presidentes se reunirá una vez al año previa convocatoria del Presidente del Gobierno, que deberá comunicarse a los miembros con una antelación mínima de veinte días naturales. La convocatoria determinará el orden del día, la fecha y el lugar de la reunión. 2. Podrán celebrarse reuniones extraordinarias cuando el Presidente del Gobierno las convoque, a iniciativa propia, o a petición de la mayoría de los Presidentes Autonómicos, que incluirá una propuesta de orden del día motivada. 3. Cuando la naturaleza de los asuntos u otras circunstancias extraordinarias lo aconsejen, el Presidente del Gobierno podrá incluir en el orden del día de las reuniones ordinarias y extraordinarias de la Conferencia temas que no hayan sido previamente examinados por el Comité preparatorio. Igualmente, y a propuesta de un tercio de los Presidentes Autonómicos (6), podrá incluirse un punto que no haya sido previamente tratado por el Comité en el orden del día de dichas reuniones».
} 
distinto del tradicional ${ }^{41}$. El orden del día que debe acompañar las convocatorias de las Conferencias es una relación de asuntos a tratar. Su importancia reside en el hecho de que resulte funcional para los debates y la posterior búsqueda de acuerdos. $Y$ por ello resulta conveniente que venga acompañado de las propuestas que se van a formular y que requieren un estudio técnico. Dicho con otras palabras, es necesario que antes de la celebración de la Conferencia, los temas hayan sido ya objeto de debate mediante el intercambio de propuestas, o en el seno de órganos preparatorios. La fijación de los temas a tratar corresponde al Presidente del Gobierno. Ahora bien, debe admitirse la posibilidad de que los Presidentes Autonómicos sugieran al Presidente del Gobierno la conveniencia de abordar determinados problemas o temas. Si estos afectan a competencias estatales, la petición autonómica no puede vincular al Presidente del Gobierno, quien libremente decidirá incluir o no el tema en el orden del día; en caso contrario, ningún inconveniente existiría en que a petición de un porcentaje determinado de presidentes se pudiera incluir un asunto concreto en el orden del día.

El Reglamento interno establece en su artículo 8 un Comité preparatorio cuya importancia en relación con el orden del día es notable ${ }^{42}$.

En todo caso, en la medida en que la convocatoria es una facultad inherente a la Presidencia, no puede ni debe configurarse como una facultad discrecional. Esto es, resulta aconsejable que se prevea la periodicidad de las reuniones. En principio, cabría defender, incluir en el diseño constitucional de la institución — como ya vimoscomo mínimo la convocatoria anual, y preferentemente la periodicidad semestral ${ }^{43}$. Intervalos superiores a un año impedirían a la Conferencia cumplir con éxito su función ${ }^{44}$. La acumulación de asuntos y problemas a tratar la desbordaría. Por ello, a nuestro juicio, resultaría aconsejable prever en su diseño constitucional, una convocatoria semestral para ambos tipos de Conferencias.

41 Como es sabido, el «orden del día» delimita jurídicamente el ámbito de cuestiones sobre las que el órgano puede pronunciarse. La inclusión en él de un determinado tema opera como requisito de validez de los actos adoptados. «En un órgano (administrativo o legislativo) colegiado —escriben Bocanegra y Huergo - lo importante es la decisión, no la reflexión (...)En cambio, en la Conferencia de Presidentes el planteamiento es exactamente el opuesto (...)Aquí es más importante la discusión que la decisión, que en todo caso será un acuerdo político y, por tanto, necesitado de ejecución o instrumentación jurídica». Bocanegra, R., y Huergo, A., La Conferencia de Presidentes, ob.cit, Pág. Pág. 101.

${ }^{42}$ El artículo 8. 3 a) tras su reforma en 2017 señala como primera función de este Comité preparatorio: «a) El examen previo de los asuntos que puedan incluirse en el orden del día de las sesiones de la Conferencia y la preparación de la documentación necesaria. En el caso de que el orden del día de la convocatoria de la Conferencia incluya algún asunto que no haya sido previamente tratado por el Comité, en cualquiera de los supuestos previstos en el apartado 3 del artículo 4, aquél se reunirá con antelación suficiente a la celebración de la correspondiente sesión de la Conferencia».

43 Ya en la Primera Conferencia celebrada en octubre de 2004 se acordó la celebración de una reunión anual, aunque dejando abierta la posibilidad de celebrar también dos al año. Como se vio esta previsión no se cumplió. Y entre 2012 y 2017 la Conferencia no se reunió ni una sola vez.

44 De forma especial, la efectiva coordinación de las Conferencias Sectoriales. 
El reglamento inicial de 2009 ya preveía la periodicidad anual, aunque la ley 49/2015 guarda silencio sobre la cuestión. En todo caso, el incumplimiento sistemático de esa previsión es el que explica que uno de los acuerdos adoptados en la VI Conferencia celebrada en 2017 haya consistido precisamente en establecer una periodicidad anual. El precedente del incumplimiento del acuerdo de 2009 planea sobre ello.

El otro elemento fundamental del diseño jurídico de las Conferencias es el relativo al régimen de adopción de acuerdos y a los efectos de estos. Como expusimos al inicio, la justificación de las Conferencias radica en la necesidad objetiva del sistema de «intentar establecer una aproximación compartida por todos en aquellas cuestiones en las que no sea en absoluto conveniente el enfrentamiento entre unas Comunidades y otras o entre todas o algunas de éstas y el Gobierno central» ${ }^{45}$. Para lograr esos objetivos, la Conferencia como órgano político no produce actos jurídicos, sino que busca la consecución de acuerdos de naturaleza igualmente política.

Todo lo expuesto hasta ahora conduce a rechazar la posibilidad de introducir el principio de votación por mayoría. No sólo porque en el caso de las Conferencias verticales, la votación misma resulta imposible por la heterogeneidad política del Presidente del Gobierno y los Presidentes Autonómicos, sino porque en ambas Conferencias, la práctica de unas votaciones que se limitaran a dejar constancia de qué Comunidades constituyen una mayoría y cuáles están en minoría no serviría absolutamente para nada.

Las Conferencias no tienen por objeto que la mayoría imponga su criterio a la minoría. Para conseguir este resultado el sistema cuenta ya con otras instituciones. La razón de ser de la Conferencia es lograr acuerdos, buscar al máximo el consenso y acercar posturas sobre problemas de todos. Cuando el acuerdo no es posible, el resultado de la Conferencia será la exposición de las posturas discrepantes, pero nunca un acuerdo mayoritario. Y ello porque un acuerdo adoptado con la oposición expresa de una o varias Comunidades, no puede ser imputable a la totalidad de ellas y tampoco puede imponerse a los discrepantes.

Con arreglo a estas premisas, el artículo 6 del Reglamento prevé que la Conferencia podrá adoptar acuerdos o recomendaciones que tendrán la consideración de compromisos políticos. Los acuerdos se adoptarán por consenso de todos los miembros presentes de la Conferencia, siempre que asistan dos tercios de los Presidentes Autonómicos (13). Las recomendaciones, por su parte, se adoptarán por el Presidente del Gobierno y dos tercios de los Presidentes Autonómicos presentes y comprometen a los miembros que las han adoptado.

En todo caso, y en relación con la posible actitud o comportamiento obstruccionista de algún Presidente Autonómico, creo que es de aplicación el deber concreto de participación leal que el Tribunal Constitucional alemán ha deducido del principio de lealtad federal: «Si en un determinado asunto es necesario un acuerdo

45 Bocanegra, R., y Huergo, A., La Conferencia de Presidentes, ob.cit...,pág. 103. 
entre Federación y Länder, se intensifica la natural obligación participativa de todas las partes, de tal forma que una objeción de uno de los participantes que obstaculice un acuerdo general y carezca de fundamentos objetivos es jurídicamente irrelevante» ${ }^{46}$. La lealtad federal fundamenta la obligación de los Presidentes Autonómicos de acudir a la Conferencia y de participar en ella con espíritu constructivo para llegar a acuerdos.

Además, por aplicación del principio general del Derecho de la buena fe, los miembros de la Conferencia quedan obligados al cumplimiento de los acuerdos, esto es a hacer todo lo posible para que sean operativos o eficaces. Esto quiere decir que, en aquellos casos en que la eficacia de los acuerdos esté subordinada a su traducción jurídica, los Presidentes Autonómicos son responsables del desarrollo normativo de los acuerdos. Desarrollo que dependerá de ellos mismos si la materia sobre la que versa el acuerdo no está reservada a la ley, y al Parlamento Autonómico en caso contrario. En este último supuesto, el Presidente tiene la obligación de recabar el respaldo de la mayoría parlamentaria para el desarrollo normativo del acuerdo. El hecho de que un posible incumplimiento de esa obligación derivada del principio de buena fe carezca de sanción jurídica no quiere decir que dicha obligación no exista. Se trataría también de una violación del principio de lealtad federal.

Otras reglas generales del funcionamiento de las Conferencias (artículo 5 del Reglamento) son la confidencialidad de las deliberaciones y la publicidad de los acuerdos. La búsqueda de acuerdos exige un cierto grado de discreción que permita a los miembros de las Conferencias llevar a cabo un intercambio de opiniones sincero. Ahora bien, terminadas las negociaciones con éxito, resulta obligado dar publicidad a los acuerdos adoptados. Aunque no se trate de textos normativos, el principio general de publicidad y transparencia de las decisiones del poder inherente al Estado de Derecho lo exige. No caben los acuerdos secretos.

\section{CONCLUSIONES: UNA PROPUESTA DE CONSTITUCIONALIZACIÓN DE LA CONFERENCIA}

El excesivo bilateralismo en la construcción del Estado Autonómico, la escasa participación de las CC.AA. en las decisiones del Estado que les afectan principalmente a ellas (como la política europea), la excesiva conflictividad territorial, constituyen, a mi juicio, aspectos de nuestro modelo de Estado susceptibles de ser mejorados. La Conferencia de Presidentes creada en 2004 puede contribuir a la resolución de todos esos problemas. La Conferencia de Presidentes permite a los Presidentes Autonómicos unir su voz a la del Presidente del Gobierno en los grandes temas de

46 Vogel, J.J. (1996): «El régimen federal de la Ley Fundamental» en Manual de Derecho Constitucional (Benda y otros) IVAP-Marcial Pons, Madrid, pág. 635. 
Estado, temas que, aunque desborden sus competencias, inevitablemente les afectan: la prevención del terrorismo, la lucha contra el crimen organizado, la inmigración, la integración europea, las directrices de la política educativa o sanitaria ${ }^{47}$.

La importante función integradora que desempeña la Conferencia aconseja, a mi juicio, dotarle de una dimensión constitucional que garantice su existencia futura y la convierta en un actor destacado del proceso político. Desde esta óptica, hay que recordar que el derecho comparado nos muestra que la relevancia de esta institución para el correcto funcionamiento de un estado políticamente descentralizado es mayor que la que reviste el Senado. Y, por tanto, no resulta justificado — desde una perspectiva constitucional - que el diseño básico de esta institución esté establecido en una ley ordinaria y de forma tan escueta.

En una futura reforma de la Constitución territorial, junto a un título dedicado al reparto de competencias, habría que incluir otro sobre el sistema de relaciones entre el poder central y los poderes territoriales. Este sería el lugar en el que habría que incluir el diseño básico de la Conferencia de Presidentes, como institución situada en la cúspide de un sistema piramidal de cooperación basado en el principio de lealtad.

El éxito futuro de este órgano dependerá fundamentalmente de la existencia de una auténtica voluntad de cooperación, pero también de su correcta institucionalización, y de su adecuada articulación con el resto de instrumentos cooperativos. La Conferencia sólo tiene sentido si se ubica en el vértice de una auténtica red piramidal de técnicas e instrumentos de cooperación territorial, entre las que destacan muy especialmente las Conferencias Sectoriales o Conferencias de un ministro con los Consejeros Autonómicos del ramo. Las relaciones entre las Conferencias Sectoriales actualmente existentes y las Conferencias de Presidentes son unas relaciones de doble dirección:

a) Por un lado, los acuerdos políticos adoptados por la Conferencia de Presidentes pueden establecer una serie de directrices sobre determinados temas, que serán después desarrollados o ejecutados por las Conferencias Sectoriales correspondientes. Esto es, los acuerdos políticos de la Conferencia de Presidentes pueden — y en ocasiones, deben- traducirse en convenios jurídicos de las Conferencias Sectoriales. En este sentido, y como ha puesto de relieve en un sugerente estudio sobre el particular, el profesor Gregorio Cámara, «las decisiones que se adoptaran en órganos y niveles inferiores de colaboración y cooperación serían mucho más eficaces, sencillamente porque estarían genéricamente orientadas y dispondrían de una fundamentación y legitimación política aun mayor». «El funcionamiento de todo el sistema — continua

47 La virtualidad de la Conferencia como instrumento de fortalecimiento e integración del Estado ha sido unánimemente destacada por la doctrina. Alberti, E. (1993): «Estado Autonómico e integración política», en Documentación administrativa, núm. 232-233, pág. 246; CÁMARA, G. (2005): «La Conferencia de Presidentes como instrumento de integración para el Estado Autonómico: problemas y perspectivas» en El estado Autonómico. Integración, solidaridad y diversidad, Colex-INAP, Madrid, Vol. I. 
el Catedrático de la Universidad de Granada- de esta manera, se vería revitalizado y las posibilidades de la colaboración, multiplicadas» ${ }^{48}$.

b) Por otro lado, puede ocurrir que en las Conferencias Sectoriales haya sido imposible llegar a un acuerdo, y las negociaciones sobre determinados temas hayan quedado bloqueadas. En esos casos, la función de la Conferencia de Presidentes es desbloquear el conflicto, y en la medida de lo posible, a través de una negociación al máximo nivel alcanzar acuerdos mínimos que puedan ser considerados como punto de partida para ulteriores debates en las Conferencias Sectoriales correspondientes.

Esa relación de complementariedad entre ambas instituciones (Conferencias Sectoriales y Conferencias de Presidentes) y entre ellas y los distintos instrumentos cooperativos (acuerdos y convenios de cooperación) confirma, en mi opinión, la necesidad de proceder a una regulación global y conjunta del marco de la cooperación territorial en España. El diseño básico de ese marco y de sus instituciones (Conferencias de Presidentes y Sectoriales) debería recogerse en el Texto Constitucional, así como la remisión expresa a una Ley General de Cooperación —a la que podría atribuírsele el carácter de orgánica dado su contenido material — para que estableciera el desarrollo legislativo de las mismas, así como del resto de procedimientos e instrumentos de cooperación. La Constitución podría recoger además no solo el sistema de cooperación vertical sino también el horizontal, y a esos efectos, incluir también la previsión de una Conferencia de Presidentes Autonómicos.

Esta constitucionalización de las Conferencias de Presidentes y del diseño básico de las relaciones de cooperación contribuiría a la consolidación del principio de lealtad federal como un principio estructural de nuestro modelo de organización territorial $^{49}$. La existencia, continuidad y regular funcionamiento de la Conferencia quedaría garantizada a nivel constitucional. El funcionamiento de esta ya no dependería - como ocurre hoy - de la coyuntura política o de la sola voluntad del presidente del Gobierno. Y, sobre, todo, su expreso reconocimiento constitucional permitiría

${ }^{48}$ Camara, G. (2004): «El principio y las relaciones de colaboración entre el Estado y las Comunidades Autónomas» en Revista de Derecho Constitucional Europeo, núm. 1, págs. 219-220.

${ }^{49}$ Y de esta forma supondrá una prueba de la madurez de nuestro sistema autonómico. Que es tanto como decir de la efectiva vigencia del principio de lealtad federal. Por ello nos obligará también a los constitucionalistas a profundizar en el estudio del significado y alcance del principio de lealtad federal en nuestro país. Porque lo cierto es que hasta ahora, y como con meridiana claridad y acierto pleno denunció el profesor Pedro De Vega: «No deja de ser sorprendente (...) que los principios de igualdad y lealtad constitucional, sin cuyo escrupuloso respeto ningún Estado compuesto puede funcionar, se hayan convertido en nuestro sistema en fórmulas retóricas, utilizadas como meras construcciones ideológicas, y ante las que la especulación jurídica se detiene y, al parecer, nada tiene que decir». DE VEGA, P. (2003): «Prólogo» a Roura, S.: Federalismo y Justicia Constitucional en la Constitución Española de 1978, Biblioteca Nueva, Madrid. Pág. 18. En este sentido, la reflexión sobre la institucionalización de la Conferencia de Presidentes nos ha puesto de manifiesto la necesidad de que el principio de lealtad federal descienda del limbo de las ideas y de la retórica al plano de la realidad, de la eficacia jurídica y de la praxis política, 
regular por ley la obligatoriedad de la asistencia, las consecuencias de la negativa a asistir, así como de cualquier otro comportamiento obstructivo, etc.

En definitiva, cuarenta años después de aprobada la Constitución, la reforma de la organización territorial es una de las más ineludibles, y en esa reforma, la concreción y el desarrollo del principio de cooperación deberían ocupar un lugar central. En el contexto de esa reforma, la constitucionalización de las Conferencias de Presidentes como la institución integradora con funciones de cooperación al máximo nivel, tendría - al margen de las consecuencias jurídicas mencionadas - un valor político y simbólico de primer orden.

Title:

The creation of the Conference of Presidents: a milestone in the evolution of the Spanish Regional State

\title{
Resumen:
}

Cuarenta años después de aprobada la Constitución, la reforma de la organización territorial es una de las más ineludibles, y en esa reforma, la concreción y el desarrollo del principio de cooperación deberían ocupar un lugar central. En el contexto de esa reforma, la constitucionalización de las Conferencias de Presidentes como la institución integradora con funciones de cooperación al máximo nivel, tendría un valor político y simbólico de primer orden. Desde esta óptica, en este artículo se examina la creación, evolución y diseño jurídico de la institución, y se analizan los principales problemas relativos a su composición y funciones, como la obligación de asistir y el modo de adopción de acuerdos.

\begin{abstract}
:
Forty years after the adoption of the Constitution, the reform of territorial organization is one of the most inescapable, and in that reform, the implementation and development of the principle of cooperation should occupy a central place. In the context of this reform, the constitutionalisation of the Conferences of Presidents as the integrating institution with functions of cooperation at the highest level, would have a political and symbolic value of the first order. From this perspective, this article examines the creation, evolution and legal design of the institution, and analyzes the main problems related to its composition and functions, such as the obligation to attend and the way of adopting agreements.
\end{abstract}


Palabras clave:

Organización territorial; Conferencia de Presidentes; Principio de cooperación; Lealtad federal.

Key words:

Territorial organization; Conference of Presidents; Principle of cooperation; Federal royalty. 